\title{
Comparison of the number of supervisors on medical student satisfaction during a child and adolescent psychiatry rotation
}

This article was published in the following Dove Press journal:

Advances in Medical Education and Practice

12 April 2016

Number of times this article has been viewed

\author{
Kelly J Mascioli' \\ Catharine J Robertson ${ }^{1,2}$ \\ Alan B Douglass ${ }^{1,3}$ \\ 'Department of Psychiatry, University \\ of Ottawa, Ottawa, ON, Canada; \\ ${ }^{2}$ Department of Psychiatry, Children's \\ Hospital of Eastern Ontario, Ottawa, \\ ON, Canada; ${ }^{3}$ Royal Ottawa Mental \\ Health Centre, University of Ottawa \\ Institute of Mental Health Research, \\ Ottawa, ON, Canada
}

Background: Traditionally, third-year medical students are assigned to one supervisor during their 1-week rotation in child and adolescent psychiatry. However, the majority of supervisory staff in the Division of Child and Adolescent Psychiatry opted to switch the supervision schedule to one in which some medical students are assigned to two primary supervisors.

Objective: The aim of the study was to determine if students assigned to two primary supervisors had greater rotation satisfaction compared with students assigned to one primary supervisor during a 1-week clerkship rotation in child and adolescent psychiatry.

Methods: A satisfaction questionnaire was sent to 110 third-year medical students who completed their child and adolescent clerkship rotation. Based on the responses, students were divided into groups depending on their number of supervisors. Questionnaire responses were compared between the groups using independent $t$-tests.

Results: When students who had one primary supervisor were compared to students who had two primary supervisors, the lone item showing a statistically significant difference was regarding improvement of assessment reports/progress notes.

Conclusion: The number of supervisors does not significantly affect the satisfaction of students during a 1-week clerkship rotation in child and adolescent psychiatry. Other factors are important in rotation satisfaction.

Keywords: medical students, clerkship, child psychiatry

\section{Introduction}

Innovations in medical education are numerous, and trainees are often invited to give their feedback on many aspects of the curriculum. Poor learning environments and unclear expectations may detract from a trainee's overall educational experience ${ }^{1}$ and may lead to curriculum revisions. The quality of the relationship between supervisor and trainee is a key factor for successful supervision, ${ }^{2}$ and clinical supervision in medicine plays a crucial role in the education of medical trainees. Clinical competence, ${ }^{2}$ good interpersonal skills, ${ }^{2}$ effective teaching of clinical skills, ${ }^{3}$ and provision of timely feedback ${ }^{2-4}$ are some of the important features of a good clinical supervisor. Nonsupervisor items such as the learning environment and workspace ${ }^{5,6}$ and the structure of the curriculum ${ }^{7}$ are also linked with trainee satisfaction. In psychiatric clinical training, seeing patients with a variety of diagnoses ${ }^{8}$ and diversity of patient settings $\mathrm{s}^{8,9}$ are indicators of rotation satisfaction.

Among Canadian medical schools, many core clerkship rotations are typically 6 weeks in duration, with a shorter duration of time allotted for subspecialty exposure. At our university, students complete a 6-week psychiatry rotation - four of these in gen-
Correspondence: Kelly ] Mascioli

Department of Psychiatry, University of Ottawa, The Ottawa Hospital - General Campus, 44I8-50I Smyth Road, Ottawa, ON KIH 8L6, Canada

$\mathrm{Tel}+$ I 6137378955

Email kmasc034@uottawa.ca 
eral adult inpatient psychiatry, 1 week in geriatric psychiatry, and 1 week in child and adolescent psychiatry.

Traditionally, third-year medical students are assigned to one supervisor during each of their psychiatry rotations, including their 1-week rotation in child and adolescent psychiatry.

The majority of supervisory staff in the department of child and adolescent psychiatry opted to switch the supervision schedule to one in which some medical students were assigned to two primary supervisors. The reason for this change was the emergence of subspecialty clinics - ie, Eating Disorders Program, to which some students were assigned for their week rotation and therefore exposed only to patients with a limited range of diagnoses and/or ages. Staff were also interested in the establishment of a paired supervisory system as it made it easier to ensure continuous supervisory coverage $-\mathrm{ie}$, one supervisor could cover the other if a deviation from the predetermined supervision schedule was required.

\section{Objective}

The objective of this study was to determine if students assigned to two primary supervisors had greater rotation satisfaction compared with students assigned to one primary supervisor during a 1-week clerkship rotation in child and adolescent psychiatry.

\section{Methods}

An e-mail was sent to 110 clerkship medical students by an administrative support person following the conclusion of students' 1-week rotation in child and adolescent psychiatry. They were invited to complete the survey, which was accessed through a link to an online Google document. Students were informed that the purpose of the study was evaluation of the clerkship supervision model and not of their performance. Participation or lack thereof did not affect their rotation evaluation, and all responses were anonymous. A reminder e-mail was sent out to students requesting they complete the survey following completion of the rotation. As an incentive to complete the survey, the students were offered a chance to win a $\$ 50$ bookstore gift card.

The study was approved by The Ottawa Hospital and Children's Hospital of Eastern Ontario Research Ethics Boards.

The initial question determined if students were assigned to one or two primary supervisors, and if they were supervised by any additional persons (Table 1). There were 15 statements of satisfaction across domains, such as relationship with supervisor, variety of patient diagnoses as well as development of interview skills, formulating hypotheses and
Table I Survey items sent to clerkship medical students

\begin{tabular}{|c|c|}
\hline A & $\begin{array}{l}\text { I was supervised by more than just my assigned supervisor(s) } \\
(\mathrm{Y} / \mathrm{N})\end{array}$ \\
\hline B & I was assigned to a single supervisor $(\mathrm{Y} / \mathrm{N})$ \\
\hline C & I was assigned to paired (two) supervisors $(\mathrm{Y} / \mathrm{N})$ \\
\hline $\mathrm{D}$ & $\begin{array}{l}\text { If you were supervised by others, how many other people } \\
\text { supervised you? }\end{array}$ \\
\hline E & If you were supervised by others, what was their profession? \\
\hline $\mathrm{F}$ & $\begin{array}{l}\text { If you were supervised by your nonsupervisor(s), was it } \\
\text { helpful? (Y/N) }\end{array}$ \\
\hline I & $\begin{array}{l}\text { I was satisfied with the amount of time I spent with my } \\
\text { supervisor. }\end{array}$ \\
\hline 2 & $\begin{array}{l}\text { I was satisfied with the variety of patient diagnoses I saw } \\
\text { during my rotation. }\end{array}$ \\
\hline 3 & $\begin{array}{l}\text { I was satisfied with what I learned about how to make child } \\
\text { and adolescent psychiatric diagnoses and treatment plans. }\end{array}$ \\
\hline 4 & $\begin{array}{l}\text { I feel my child and adolescent diagnostic and treatment plan } \\
\text { skills have improved as a result of this supervision. }\end{array}$ \\
\hline 5 & $\begin{array}{l}\text { I was satisfied with what I learned about child and adolescent } \\
\text { psychiatry interview skills. }\end{array}$ \\
\hline 6 & $\begin{array}{l}\text { I feel my child and adolescent psychiatric interview skills } \\
\text { improved as a result of this rotation. }\end{array}$ \\
\hline 7 & $\begin{array}{l}\text { I was satisfied with what I have learned about child and } \\
\text { adolescent assessment reports and/or progress notes. }\end{array}$ \\
\hline 8 & $\begin{array}{l}\text { I feel my child and adolescent assessment reports and/or } \\
\text { progress notes have improved as a result of this supervision. }\end{array}$ \\
\hline 9 & I am satisfied that I achieved the objectives for the rotation. \\
\hline 10 & $\begin{array}{l}\text { During this rotation, my supervisor(s) ensured my time was } \\
\text { used efficiently. }\end{array}$ \\
\hline 11 & I feel my supervisor was happy to supervise me. \\
\hline 12 & $\begin{array}{l}\text { My supervisor(s) helped me formulate hypotheses rather than } \\
\text { just acquire facts. }\end{array}$ \\
\hline 13 & $\begin{array}{l}\text { I feel this rotation prepared me well for the child and } \\
\text { adolescent psychiatry exam questions. }\end{array}$ \\
\hline 14 & $\begin{array}{l}\text { I was satisfied with the amount of knowledge I gained } \\
\text { regarding multidisciplinary teams. }\end{array}$ \\
\hline 15 & $\begin{array}{l}\text { Overall, I was satisfied with this I-week rotation in child and } \\
\text { adolescent psychiatry. }\end{array}$ \\
\hline
\end{tabular}

Notes: A-F = Group membership items; I-15 = Satisfaction items, scored on a Likert scale I-4.

making diagnoses, treatment plans, assessment and progress notes, exposure to multidisciplinary teams, achieving overall objectives, preparation for exam questions, and overall sense of satisfaction (Table 1). Students were asked to rate how much they agreed or disagreed with each statement on a Likert scale from 1 to 4 .

Based on their responses, students were divided into the following groups: 1) students assigned to one primary supervisor, including extra or informal supervisors; and 2) students assigned to two primary supervisors, including extra or informal supervisors. Extra and informal supervi- 


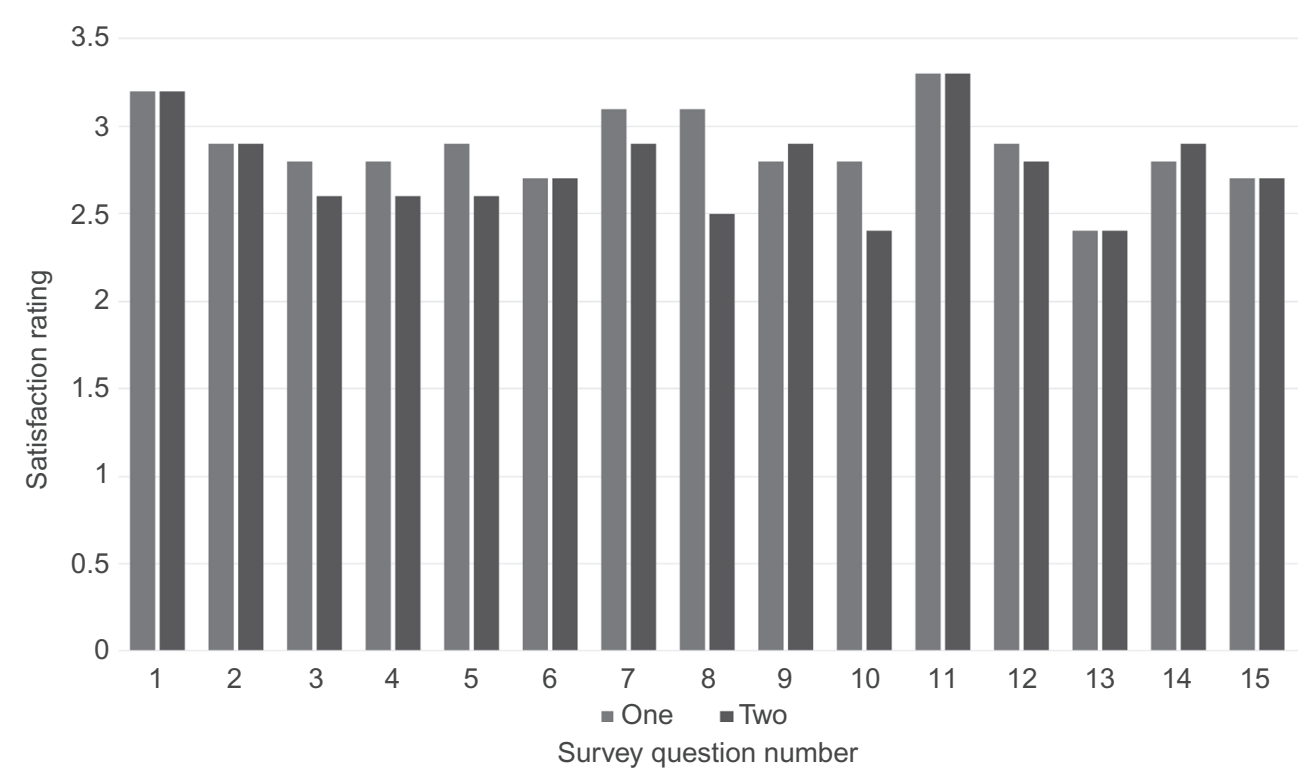

Figure I Mean of satisfaction items: one vs two supervisors.

sors included residents, other psychiatrists, and allied health care professionals.

The item results were totaled for each participant to give an overall satisfaction rating for each student. Mean, median, and standard deviation were also calculated for each Likert scale item across each group. An independent $t$-test was performed for each item between the groups analyzed.

\section{Results}

A total of 60 students responded to the survey; however, two participants were excluded as they failed to complete the survey properly (Figure 1). Overall, $58 / 110=52.7 \%$ of responses were analyzed. Thirty-six students who were assigned to two supervisors, and 22 students assigned to one supervisor replied to the survey (Figure 1). Students in the one-supervisor group received the highest satisfaction scores with an overall mean of 2.9, compared with 2.7 for the two-supervisor group (Table 2). The highest rated question was item 11: "I feel my supervisor was happy to supervise me" with a mean of 3.2 for the one-supervisor group and a mean of 3.3 for the two-supervisor group (Table 2). The lowest rated question was item 13: "I feel this rotation prepared me well for the child and adolescent psychiatry exam questions" with a mean of 2.6 for the one-supervisor group and 2.4 for the two-supervisor group. Students with one primary supervisor felt their assessment reports and/or progress improved compared with students assigned to two primary supervisors, $P=0.02$ (Table 2). There were no other statistically significant differences found between the groups.
Table 2 Mean and $P$-values of satisfaction items between groups analyzed

\begin{tabular}{llll}
\hline Item & $\begin{array}{l}\text { Mean, one } \\
\text { supervisor }\end{array}$ & $\begin{array}{l}\text { Mean, two } \\
\text { supervisors }\end{array}$ & P-value \\
\hline I & 3.2 & 3.0 & 0.68 \\
2 & 3.0 & 2.8 & 0.74 \\
3 & 2.9 & 2.6 & 0.17 \\
4 & 2.9 & 2.6 & 0.19 \\
5 & 3.0 & 2.6 & 0.09 \\
6 & 2.9 & 2.6 & 0.17 \\
7 & 3.1 & 2.9 & 0.14 \\
8 & 3.1 & 2.6 & $0.02 *$ \\
9 & 2.9 & 2.8 & 0.28 \\
I0 & 2.9 & 2.4 & 0.08 \\
II & 3.2 & 3.3 & 0.58 \\
I2 & 3.0 & 2.8 & 0.18 \\
I3 & 2.6 & 2.4 & 0.19 \\
I4 & 2.9 & 2.9 & 0.35 \\
I5 & 2.8 & 2.7 & 0.63 \\
Overall average & 2.9 & 2.7 & \\
\hline Notes: & 2.9 &
\end{tabular}

Notes: *Indicates that the result was statistically significant, $P<0.05$.

\section{Discussion}

To our knowledge, this is the first study that assessed medical students' rotation satisfaction based on the number of supervisors. There are some limitations to this study. There was a lack of demographic questions; it is therefore unclear if the groups were similar, or if demographics played any role in rotation satisfaction. The moderate response rate may have given rise to sampling bias. Also, two study participants did not complete questions properly, leading to exclusion from the data analysis. Furthermore, this study may have been underpowered to detect 
a significant difference. Because we made 15 comparisons, it is possible that the single significant difference that we found was, in fact, due to chance. This was explored using the Holm-Bonferroni procedure for multiple comparisons, ${ }^{10}$ and in fact this item was not significant after that procedure. Thus, based on the results, there was no statistically significant difference in medical student satisfaction based on the number of supervisors. Moreover, students may require at least 1 week to adapt to a supervisor's particular style of teaching, and this may have accounted for the lack of difference and perhaps slightly lower satisfaction rates in the two-supervisor group compared with the one-supervisor group. Other factors can be important in rotation satisfaction, such as opportunity to examine patients independently; quality of supervision and quantity of feedback; supervisor and multidisciplinary staff's attitude toward students and teaching; number of other learners; and degree of rotation organization. ${ }^{11}$

Given the limitations of the study, it is difficult to draw useful conclusions. Future research is needed with a larger sample size. Knowledge gained from this study may be helpful when designing clinical rotations, given that the number of assigned supervisors during a 1-week rotation may not significantly influence medical student satisfaction.

\section{Acknowledgments}

This study was supported administratively by the Department of Psychiatry, University of Ottawa, The Children's Hospital of Eastern Ontario, and The Ottawa Hospital. We would also like to thank all of the medical students who participated, the University of Ottawa Department of Psychiatry resident research mentor Dr Simon Hatcher, as well as the University of Ottawa library services.

\section{Disclosure}

The authors report no conflicts of interest in this work.

\section{References}

1. Albanese M. Students are not customers: a better model for medical education. Acad Med. 1999;74(11):1172-1186.

2. Kilminster SM, Jolly BJ. Effective supervision in clinical practice settings: a literature review. Med Educ. 2000;34(10):827-840.

3. Kernan WN., Lee MY, Stone SL, Freudigman KA, O'Conner PG. Effective teaching for preceptors of ambulatory care: a survey of medical students. Am J Med. 2000;108(6):499-502.

4. Remmen R, Denekens J, Scherpbier A, et al. An evaluation study of the didactic quality of clerkships. Med Educ. 2000;34(6):460-464.

5. Blazek BA, Zollinger TW, Look KY. Obstetrics-gynecology resident satisfaction. Am J Obstet Gynecol. 2005;193(5):1798-1803.

6. Cannon GW, Keitz SA, Holland GJ, et al. Factors determining medical students' and residents' satisfaction during VA-based training: findings from the VA Learners' Perceptions Survey. Acad Med. 2008;83(6):611-620.

7. Robins LS, Gruppen LD, Alexander GL, Fantone JC, Davis WK. A predictive model of student satisfaction with the medical school learning environment. Acad Med. 1997;72(2):134-139.

8. Fox HA, McGahee CL, Bluestone H. Quality in a psychiatric clerkship. Hillside J Clin Psychiatry. 1981;3(2):177-185.

9. Ellencweig N, Weizman A, Fischel T. Factors determining satisfaction in psychiatry training in Israel. Acad Psychiatry. 2009;33(2):169-173.

10. Holm S. A simple sequentially rejective multiple test procedure. Scand J Stat. 1979:6(2):65-70.

11. Dolmans DH, Wolfhagen IH, Heineman E, Scherpbier AJ. Factors adversely affecting student learning in the clinical learning environment: a student perspective. Educ Health. 2008;21(3):32. 